https://www.journal-imab-bg.org

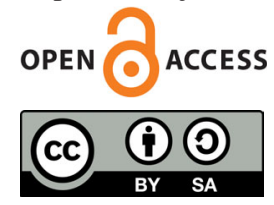

Original article

\title{
SKELETAL AGE ASSESSMENT IN PATIENTS WITH TRANSVERSE MAXILLARY DEFICIT UNDERGOING RAPID MAXILLARY EXPANSION
}

\author{
Mariya Stoilova-Todorova, Silviya Krasteva, Georgi Stoilov \\ Department of Orthodontics, Faculty of Dental Medicine, Medical University of \\ Plovdiv, Bulgaria
}

\begin{abstract}
:
Aim: The study was governed by two main goals: 1) To assess the skeletal maturation of young patients who were undergoing orthodontic treatment with rapid maxillary expansion; 2) To compare their chronological age with their skeletal maturation stage.

Material and methods: Lateral cephalometric radiographs of 74 patients were randomly selected and analyzed. The sample included 51 girls and 23 boys in late mixed and permanent dentition, with an average age of 13.2 $( \pm 2.24)$ in the range from 9 to 17 years. The assessment of skeletal maturation followed the cervical vertebral maturation (CVM) methods of Baccetti et al. and Lamparski.
\end{abstract}

Results: The results showed 53\% consistency and $47 \%$ discrepancy between the chronological and skeletal age of the patients. In the age group 9-13.5 years, the discrepancies reached $73.5 \%$. The difference in percentages was statistically significant, $p<.001$. The discrepancies tended towards higher skeletal age: $80 \%$ in the whole sample and $86.25 \%$ among patients aged $9-13.50$ years. The difference between the patients classified in higher and lower stages of skeletal age was statistically significant, $p$ $<.001$.

Conclusion: Chronological age is an unreliable indicator of growth potential in adolescent patients before and after growth spurt. The discrepancy is particularly prominent in patients before growth spurt, where skeletal age suggests a higher level of maturation than predicted by the patients' chronological age.

Keywords: Cervical vertebral maturation, Skeletal maturity, Chronological age, Rapid maxillary expansion

\section{INTRODUCTION:}

The development of a successful plan for orthodontic treatment involves a thorough assessment of the type of malocclusion and patient's growth potential, which may negatively or positively affect the treatment outcomes.

The biological aspects of growth in the maxillo-facial area are fundamental elements of the overall growth potential with large variations among patients. The onset of puberty spurt growth, the maximum growth spurt and its duration vary considerably in individuals of a similar age group.

Human growth and development, although following a common growth model, vary among different individuals with intervals of accelerated growth, followed by decelerating growth. The maturational stage of a patient can have a significant impact on the development of the best treatment plan for the patient. The timing of orthodontic treatment and the choice of a treatment method (extraction or non-extraction) are determined exclusively by a patient's growth type and remaining growth potential [1].

Previous research has revealed different indicators of an individual's maturation. All indicators are used in order to determine the optimum timing for orthodontic treatment in view of growth modifications. Borderline cases may also benefit from an assessment of the remaining growth potential [2]. According to some authors a significant discrepancy exists between the chronological, skeletal and dental age of patients $[3,4,5]$. Skeletal maturation is more closely related to facial growth rate than chronological age [1].

Two well established methods for determining skeletal maturation are the classical

$\mathrm{X}$-ray of the hand-wrist bone and the more recent method of lateral cephalogram $[6,7,8,9]$. Studies have shown a significant correlation between the results shown by X-rays of the hand-wrist bone and the cervical vertebrae evaluation method (CVM) $[10,11,12]$. Based on their findings, it has been concluded that the cervical vertebrae evaluation method is a valid indicator of skeletal growth and can be used with the same degree of credibility as the commonly accepted X-ray of the hand-wrist bone [10, 13, 14]. Moreover, CVM is a safer and easier method than the hand-wrist method assessment, which requires the identification of specific ossification nuclei on the hand-wrist bones.

Based on the findings of previous studies, it appears that chronological age is a rather weak predictor of growth potential as opposed to the skeletal age assessment which is an indicator for the actual growth status of the patient. This fact resents a problem for orthopedic treatment with rapid maxillary expansion which is heavily dependent on the precise estimation of growth potential for attainment of the best treatment outcomes. Therefore, we set up to further examine this issue with a sample of young Bulgarian patients who were undergoing orthodontic treatment with rapid max- 
illary expansion. We were specifically interested in finding the level of consistency and discrepancy between their chronological and skeletal age. We envisioned the results would help us in the proper diagnosis and treatment planning of future patients.

\section{MATERIALS AND METHOD:}

The study sample included 74 patients with transverse maxillary deficit undergoing treatment at the Faculty of Dental Medicine, Plovdiv and a private practice. The patients' age ranged from 9 to 17 years with a mean age of 13.2 ( \pm 2.24 ), with 51 girls and 23 boys. All patients were in the late transitional or early permanent dentition stage. To evaluate the skeletal age of the patients, we used lateral cephalometric radiograms, which had to satisfy the following criteria:

- The radiographs are clear and made according to the commonly accepted methodology for performing lateral cephalograms.

- The vertebrae do not have morphological changes and are not affected by systemic diseases.

- All vertebrae C2 through C6 have visible borders.

We assessed skeletal age through changes in cervical vertebral development by combining the method proposed by Lamparski [9] with the modified method of Bacchetti, Franchi and Mc Namara [15]. For precise cephalometric morphological characterization, we applied points determined by the Bacchetti methodology on the $\mathrm{C} 2, \mathrm{C} 3$, and $\mathrm{C} 4$ vertebrae $[6,15]$. For more precise assessment, we supplemented the methodology with the addition of identical points on the $\mathrm{C} 5$ and $\mathrm{C} 6$ vertebrae.

The presence of concavity was determined at the following points: $\mathrm{C} 2 \mathrm{~m}, \mathrm{C} 3 \mathrm{~m}$ and $\mathrm{C} 4 \mathrm{~m}$, located higher than the line connecting points $\mathrm{C} 2 \mathrm{p}, \mathrm{C} 2 \mathrm{a}, \mathrm{C} 3 \mathrm{lp}, \mathrm{C} 3 \mathrm{la}$, and respectively points C51p, C5la, C6up and C6ua.

\section{Statistical methods:}

The data analysis was performed with Version 24 (2016) of the Statistical Package for the Social Sciences
(SPSS). Statistics included frequencies, percentages and comparisons of proportions through chi-square tests. Statistical significance was considered at Type I error rate alpha $\leq 0.5$.

\section{RESULTS:}

Skeletal age was categorized into six stages: Stage 1 (10 year olds) - two years before growth spurt; Stage 2 (11 year olds) - one year before growth spurt; Stage 3 (12year-olds) - associated with growth spurt; Stage 4 (13-yearolds) - the year after growth spurt; Stage 5 (14-year-olds) - one year after growth spurt; Stage 6 (15 years old) - two years after growth spurt. The distribution of patients among the six skeletal age stages and the two genders is given below. It should be noted that the proportions of male and female patients in each stage were not significantly different.

- Stage 1: $6.8 \%$ of the patients, $5.9 \%$ girls and $8.7 \%$ boys, $p=0.64$.

- Stage 2: $9.5 \%$ of the patients, $5.9 \%$ girls and $17.4 \%$ boys, $p=0.13$.

- Stage 3: $13.5 \%$ of the patients, $13.7 \%$ girls and $13 \%$ boys, $p=0.91$.

- Stage $4: 17.6 \%$ of the patients, $19.6 \%$ girls and $13 \%$ boys, $p=0.52$.

- Stage 5: $24.3 \%$ of the patients, $23.5 \%$ girls and $26.15 \%$ girls, $p=0.78$.

- Stage 6: $28.4 \%$ of the patients, $31.4 \%$ girls and 21.75 boys, $p=0.37$.

Patients' chronological age was coded in years and months. Months were represented in fractions as follows: $0.25=\leq 3$ months; $0.50=\leq 6$ months; $0.75=>6$ and $\leq 9$ months. Seven age groups were formed, including: 9-10.50; $10.75-11.50 ; 11.75-12.50 ; 13.75-14.50 ; 14.75-15.50$; $15.75-17$.

The cross-tabulation table of skeletal and chronological age is presented in Table 1.

Table 1. Cross-tabulation table of patients' chronological and skeletal age

\begin{tabular}{|c|c|c|c|c|c|c|c|}
\hline \multirow[t]{2}{*}{ Age Group } & & \multicolumn{6}{|c|}{ Skeletal Age } \\
\hline & & Stage 1 & Stage 2 & Stage 3 & Stage 4 & Stage 5 & Stage 6 \\
\hline \multirow[t]{2}{*}{$9.00-10.50$} & $\mathrm{~N}$ & 4 & 7 & 1 & 0 & 0 & 0 \\
\hline & $\%$ & $33 \%$ & $58 \%$ & $9 \%$ & $0 \%$ & $0 \%$ & $0 \%$ \\
\hline \multirow[t]{2}{*}{$10.75-11.50$} & $\mathrm{~N}$ & 1 & $\mathbf{0}$ & 3 & 2 & 0 & 0 \\
\hline & $\%$ & $17 \%$ & $0 \%$ & $50 \%$ & $33 \%$ & $0 \%$ & $0 \%$ \\
\hline \multirow[t]{2}{*}{$11.75-12.50$} & $\mathrm{~N}$ & 0 & 0 & 3 & 4 & 2 & 0 \\
\hline & $\%$ & $0 \%$ & $0 \%$ & $33 \%$ & $45 \%$ & $22 \%$ & $0 \%$ \\
\hline \multirow[t]{2}{*}{$12.75-13.50$} & $\mathrm{~N}$ & 0 & 0 & 3 & 6 & 5 & 1 \\
\hline & $\%$ & $0 \%$ & $0 \%$ & $20 \%$ & $40 \%$ & $33 \%$ & $7 \%$ \\
\hline
\end{tabular}




\begin{tabular}{cccccc|c|c|c|}
\hline \multirow{2}{*}{$13.75-14.50$} & $\mathrm{~N}$ & 0 & 0 & 0 & 1 & $\mathbf{9}$ & 3 \\
\cline { 2 - 8 } & $\%$ & $0 \%$ & $0 \%$ & $0 \%$ & $8 \%$ & $\mathbf{6 9 \%}$ & $23 \%$ \\
\hline \multirow{2}{*}{$14.75-15.50$} & $\mathrm{~N}$ & 0 & 0 & 0 & 0 & 2 & $\mathbf{4}$ \\
& $\%$ & $0 \%$ & $0 \%$ & $0 \%$ & $0 \%$ & $33 \%$ & $\mathbf{6 7 \%}$ \\
\hline
\end{tabular}

Fractions represent months as follows: $0.25=\leq 3$ months; $0.50=\leq 6$ months; $0.75=>6$ and $\leq 9$ months.

The cells showing agreement between the two are shaded. Discrepancies are obvious, especially in the first four chronological age groups. In the three older groups (ages 13.75 through 17), the percentage of agreement/consistency increased and reached $100 \%$ in the oldest group.

As a whole, 39 patients (53\%) showed consistency in chronological and skeletal age, and 35 patients (47\%) exhibited discrepancy. Of the discrepancies, 7 (20\%) were towards a lower skeletal class and $28(80 \%)$ were towards a higher skeletal class. The difference of $60 \%$ was statistically significant, $\chi 2(1)=24.840, p<.001$.
Fractions represent months as follows: $0.25=\leq 3$ months; $0.50=\leq 6$ months; $0.75=>6$ and $\leq 9$ months.

Chi-square comparison of the proportions of consistency and discrepancy between chronological and skeletal age (Table 2) showed that in the first four chronological age groups, the percentage of discrepancy was significantly higher than the percentage of consistency: age group 910.50 years, $p<0.001$; age group $10.75-11.50$ years, $p<$ 0.001 ; age group $11.75-12.50$ years, $p<0.001$; age group $12.75-13.50$ years, $p=0.015$.

Table 2. Proportional comparison of the consistency and discrepancy between chronological and skeletal age.

\begin{tabular}{llcccc}
\hline & Age Groups & $\begin{array}{c}\% \\
\text { consistency }\end{array}$ & $\begin{array}{c}\% \\
\text { discrepancy }\end{array}$ & $\begin{array}{c}\chi_{2} \\
\text { (df 1) }\end{array}$ & p-value \\
\hline 1. & $9.00-10.50$ & $33 \%$ & $67 \%$ & 16.993 & $.000^{* *}$ \\
2. & $10.75-11.50$ & $0 \%$ & $100 \%$ & 147.00 & $.000^{* *}$ \\
3. & $11.75-12.50$ & $33 \%$ & $67 \%$ & 16.993 & $.000^{* *}$ \\
4. & $12.75-13.50$ & $40 \%$ & $60 \%$ & 5.88 & $.015^{*}$ \\
5. & $13.75-14.50$ & $69 \%$ & $31 \%$ & 21.22 & $.000^{* *}$ \\
6. & $14.75-15.50$ & $67 \%$ & $33 \%$ & 16.993 & $.000^{* *}$ \\
7. & $15.75-17.00$ & $100 \%$ & $0 \%$ & 147.00 & $.000^{* *}$ \\
\hline
\end{tabular}

** Statistical significance at alpha $=.01 ; *$ Statistical significance at alpha $=.05$

The trend changed in the three older groups. The percentage of consistency was significantly higher than the percentage of discrepancy in age group 13.75-14.50 years $(p<0.001)$ and in age group 14.75-15.50 years, $p<0.001$. In the oldest group (15.75 -17 years) no discrepancies were recorded as there was a complete match between chronological and skeletal age.

The two opposing trends described so far can be linked to the different position of the younger and older groups in relation to growth spurt. The first four age groups (ages 9 to 10.50) were either before growth spurt or had entered it, whereas the three older groups (ages 10.75-17) had already passed growth spurt age. This observation mo- tivated us to form two new groups by merging together the four younger age groups and the three older age groups. Group I included 42 patients before and around growth spurt, in the age range between 9 and 13.5 years, with unformed permanent dentition. Group II consisted of 32 patients, after growth spurt, with ages ranging between 14 and 17 years, with permanent dentition

We compared these two new age groups in relation to the percentage of consistency and discrepancy between chronological and skeletal age. The percentage of consistency in the group before growth spurt was $26.5 \%$, whereas it was $78.6 \%$ in the group after growth spurt. The difference was statistically significant, $\chi 2=19.461, p<0.001$. Discrepancies showed an opposite trend. A statistically 
higher percentage was observed in the group before growth spurt $(73.5 \%)$ as compared to $21.4 \%$ in the group after growth spurt. The difference of $52.1 \%$ was statistically significant, $\chi 2=19.461, p<0.001$. Figure 1 illustrates the opposing trend of consistency and discrepancy between chronological and skeletal age in the patients before and after growth spurt.

Fig. 1. Percentage of consistency and discrepancy between chronological and skeletal age. Patients before growth spurt show significantly higher percentage of discrepancy

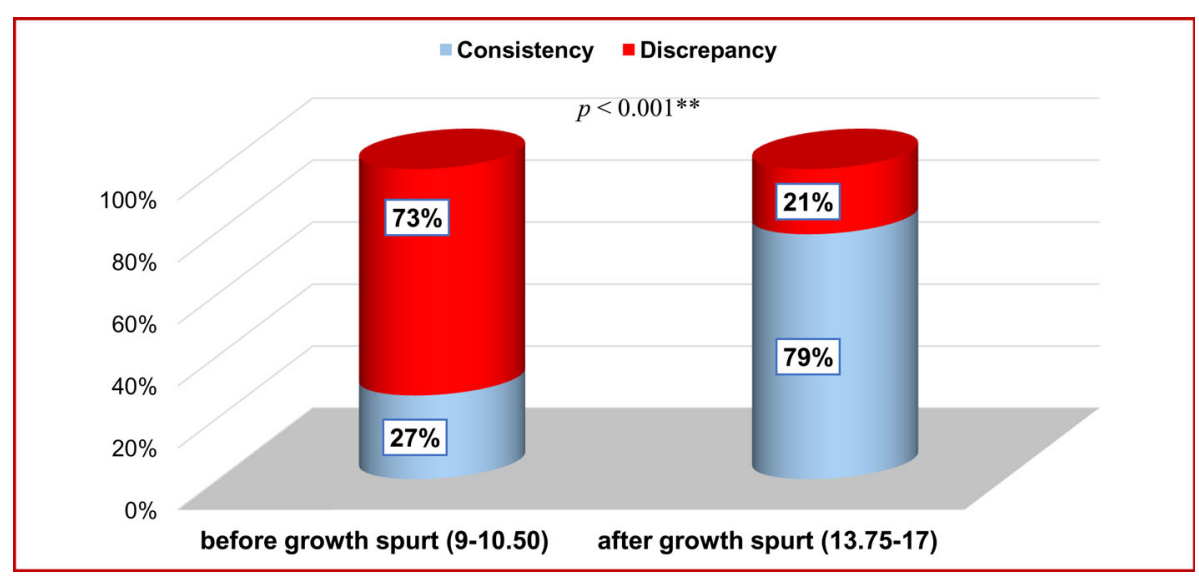

The statistically significant percentage of discrepancy in the group before growth spurt prompted us to conduct further analysis in order to establish the direction of the discrepancy between chronological and skeletal age. We compared the percentage of patients within this group who were categorized in lower skeletal class than predicted by their chronological age with the percentage of patients who were categorized in a higher skeletal class (Figure 2). The results for age group 9-10.50 years showed 67\% discrepancy between chronological and skeletal age, of which

$100 \%$ was towards a higher skeletal age, and $0 \%$ towards a lower skeletal age stage. For age group 10.75-11.50 years, the discrepancy rate was $100 \%$, of which $83 \%$ towards a higher skeletal age and $17 \%$ towards a lower skeletal age. In age group $11.75-12.50$ years, the percentage of discrepancy was $67 \%$, with $100 \%$ of the discrepancies being towards a higher skeletal age. The percentage of discrepancy in age group 12.75 - 13.50 years was $60 \%$, of which $62 \%$ towards a higher skeletal age and $38 \%$ towards a lower skeletal age.

Fig. 2. Percentage of discrepancy towards higher and lower stage of skeletal age in the age group 9-13.50 years

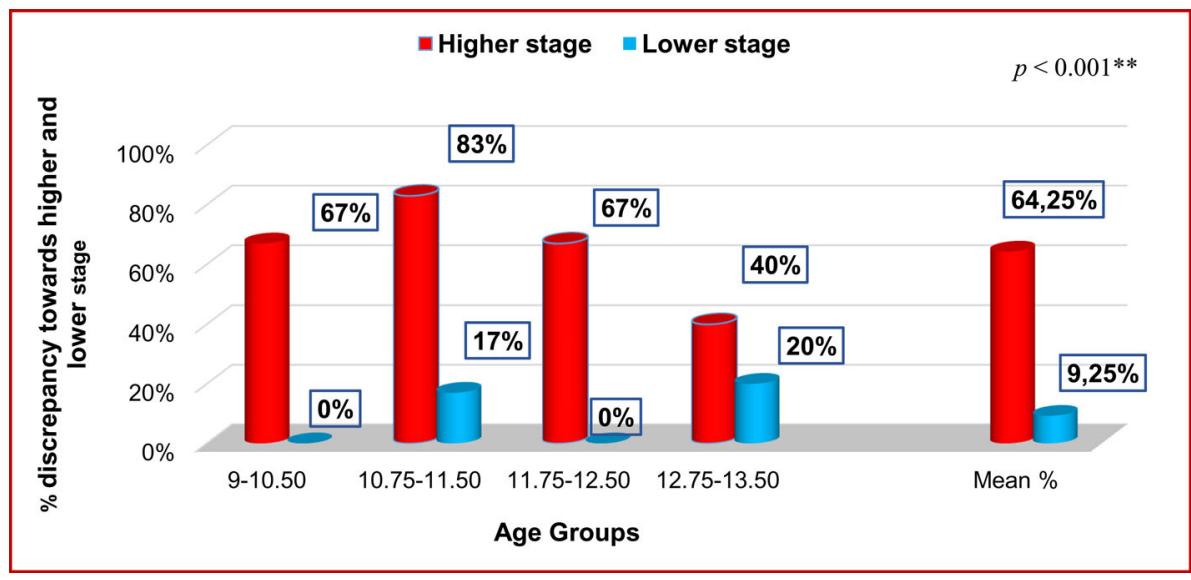

The mean rate of discrepancy in the age group 9- tistically significant, $\chi 2(1)=32.749, p<.001$. 13.50 years was estimated at $73.25 \%$, of which $86.25 \%$ towards a higher skeletal age and $13.75 \%$ towards a lower skeletal age. The difference between the mean percentage of patients in the age group 9-13.5 years who were classified in a higher skeletal age and lower skeletal age was sta-

\section{DISCUSSION:}

In orthodontics, the development of an optimal treatment plan for adolescent patients requires growth modification in order to take advantage of the growth benefits and to 
correct skeletal discrepancies. Baccetti et al. [7] implemented for the first time the CVM method for assessing skeletal maturation by tracking short and long-term craniofacial changes in patients treated with a rapid maxillary expansion appliance. The authors found that therapy with the Haas expander resulted in a significant increase in intermolar width in both study groups, before and after growth spurt, with a greater increase in lateronasal width in patients before growth spurt. On this basis, they concluded that rapid expansion treatment is more effective when applied to patients before growth spurt because it leads to skeletal level changes in the long-term relationship of maxillary and surrounding structures. When applying protocols for rapid maxillary expansion after growth spurt, the maxillary adaptation mechanisms for expansion therapy have an effect but shift from skeletal to dental-alveolar level.

These findings show that precision in assessing skeletal maturation is of primary importance for the selection of the best treatment options. Chronological age has been found as weak predictor of skeletal maturation by previous research Safavi et al. [16], Baidas [17]. Our results corroborate their findings as we established a high rate of discrepancy between chronological and skeletal age. In the whole sample the discrepancy rate was $47 \%$, however in the age group before growth spurt $(9-13.50)$ it reached $73.50 \%$.

We also established that the discrepancies tend to be towards a higher skeletal class. In the whole sample, $80 \%$ was towards a higher skeletal age and $20 \%$ towards a lower skeletal age. In the age range of 9 to 13.50 years, which spans the period before growth spurt, the total percentage of discrepancy towards a higher skeletal age was $86.25 \%$ with $13.75 \%$ towards a lower skeletal age.
Extrapolating from these results, we claim that chronological age is a weak indicator of skeletal maturation in patients before growth spurt. The rate of discrepancy is statistically significant in the age group before growth spurt. Moreover, the discrepancy tends to be towards a higher skeletal age than predicted by chronological age.

As a whole, our results are not new; they support a claim that has already been made. However, our contribution is that for the first time (at least to our knowledge) the discrepancy between chronological and skeletal age has been investigated with a sample of Bulgarian patients. We have also contributed to the understanding of the direction of discrepancy which tends to be towards a higher skeletal class, especially in patients before growth spurt.

\section{CONCLUSION:}

Chronological age is an unreliable indicator of skeletal maturation. It shows a high rate of false maturational stage classification, which can negatively affect the outcomes of orthodontic treatment.

In patients with incomplete skeletal growth, a more advanced stage of skeletal maturation is observed than predicted by chronological age. The advancement proves the process of acceleration among adolescents.

The combined method of cervical vertebral maturational status is reliable method for assessing the individual skeletal maturity of the patient, which help orthodontists adjust treatment plans as appropriate. We recommend the combination of methods in evaluating skeletal maturation in order to obtain more precise estimation of a patient's skeletal stage.

\section{REFERENCES:}

1. Björk A, Helm S. Prediction of the age of maximum puberal growth in body height. Angle Orthod. 1967 Apr;37(2):134-43. [PubMed]

2. Mutinelli S, Cozzani M. Rapid maxillary expansion in contemporary orthodontic literature. APOS Trends Orthod. 2016 May;6(3):129-36. [CrossRef]

3. Fishman LS. Chronological versus skeletal age, an evaluation of craniofacial growth. Angle Orthod. 1979 Jul;49(3):181-9. [PubMed]

4. Cericato GO, Bittencourt MAV, Paranhos LR. Validity of the assessment method of skeletal maturation by cervical vertebrae: a systematic review and meta-analysis. Dentomaxillofac Radiol. 2015 Feb;44(4): 20140270. [PubMed]

5. Lund E, Tommervold T. Relationship between dental age, skeletal maturity and chronological age in young orthodontic patients [dissertation]. The Arctic University of Norway; 2014. 14p.

6. Baccetti T, Franchi L, McNamara JA. An improved version of the cervical vertebral maturation (CVM) method for the assessment of mandibular growth. Angle Orthod. 2002 Aug;72(4):316-23. [PubMed]

7. Baccetti T, Franchi L, Cameron CG, McNamara JA. Treatment timing for rapid maxillary expansion. Angle Orthod. 2001 Oct; 71(5):343-50. [PubMed]

8. Hägg U, Taranger J. Maturation indicators and the pubertal growth spurt. Am J Orthod. 1982 Oct;82(4): 299-309. [PubMed]

9. Lamparski DG. Skeletal age assessment utilizing cervical vertebrae [dissertation]. [Pittsburgh (PA)]: Uni- versity of Pittsburgh; 1972.

10. Özer T, Kama JD, Ozer SY. A practical method for determining pubertal growth spurt. Am J Orthod Dentofacial Orthop. 2006 Aug; 130(2):131.e1-6 [PubMed]

11. Uysal T, Ramoglu SI, Basciftci FA, Sari Z. Chronologic age and skeletal maturation of the cervical vertebrae and hand-wrist: is there a relationship? Am J Orthod Dentofacial Orthop. 2006 Nov;130(5):622-8. [PubMed] [CrossRef]

12. Wong RW, Alkhal HA, Bake A, Rabie M. Use of cervical vertebral maturation to determine skeletal age. Am J Orthod Dentofac Orthop. 2009 Oct;136(4):484.e1-6 [PubMed]

13. Flores-Mir C, Burgess A, Champney C, Jensen MJ, Pitcher RR, Major PJ. Correlation of Skeletal Maturation Stages Determined by Cer- 
vical Vertebrae and Hand-wrist Evaluations. Angle Orthod. 2006 Jan; 76(1):1-5. [PubMed]

14. Durka-Zaj ${ }^{1} \mathrm{c}$ M, Marcinkowska A, Mituœ-Kenig M. Bone age assessment using cephalometric photographs. Pol J Radiol. 2013 Apr-Jun; 78(2):19-25. [PubMed]

15. Baccetti T, Franchi L,
McNamara JA. The Cervical Vertebral Maturation (CVM) method for the assessment of optimal treatment timing in dentofacial orthopedics. Semin Orthod. 2005 Sep;11(3): 119-129. [Crossref] 16. Safavi SM, Beikaii H, chronological age in Saudi adolesHassanizadeh R, Younessian F, cents. King Saud Univ J Dent Sci. Baghban AA. Correlation between 2012 Jan;3(1):21-26. [CrossRef]

Please cite this article as: Stoilova-Todorova M, Krasteva S, Stoilov G. Skeletal age assessment in patients with transverse maxillary deficit undergoing rapid maxillary expansion. J of IMAB. 2018 Jul-Sep;24(3):2113-2118.

DOI: https://doi.org/10.5272/jimab.2018243.2113

Received: 02/04/2018; Published online: 21/08/2018

Address for correspondence:

Mariya Georgieva Stoilova-Todorova

Department of Orthodontics, Faculty of Dental Medicine, Medical University of Plovdiv.

3, Hristo Botev Blvd., 4000 Plovdiv, Bulgaria

E-mail: marchela_stoilova@abv.bg 